\title{
The level of mental workload related to the index of difficulty of the motor task and handedness
}

\section{NATÁLIA LELIS-TORRES | HERBERT UGRINOWITSCH | MAICON RODRIGUES ALBUQUERQUE | TÉRCIO APOLINÁRIO-SOUZA | GUILHERME MENEZES LAGE}

School of Physiotherapy, Ocupational Therapy and Physical Education, Universidade Federal de Minas Gerais, BRAZIL.

Correspondence to: Natália Lelis-Torres, Escola de Educação Física, Fisioterapia e Terapia Ocupacional - EEFFTO, Universidade Federal de Minas Gerais, av. Presidente Antônio Carlos, 6627 - Belo Horizonte/MG, BRAZIL.

email: natalialelis.torres@gmail.com

\author{
AT A GLANCE \\ We investigate if the performance decline \\ observed when the task ID is high or when the \\ task is performed with non-dominant hand \\ could be associated to a higher degree of \\ mental resources dedicated to execution of the \\ task. Only the ID factor markedly influenced \\ the mental workload.

$\begin{array}{ll}\text { ABBREVIATIONS } \\ \text { DFA } & \text { discriminant function analysis } \\ \text { EEG } & \text { electroencephalographic } \\ \text { ID } & \text { index of difficulty } \\ \text { MT } & \text { movement time } \\ \text { PSD } & \text { power spectral density }\end{array}$

PUBLICATION DATA

Received 05/09/2017

Accepted 13/12/2017

Published 14/12/2017

\begin{abstract}
BACKGROUND: Manual movements are affected by the index of difficulty of the task and handedness. High index of difficulty and execution with the non-dominant hand can increase the mental workload.

AIM: This study investigated the relation between the level of mental workload, the index of difficulty of the task, and handedness in manual movements.

METHOD: Twenty-three right-handed male students $(24.1 \pm 4.3$ years) participated in this study. The index of difficulty in the Grooved Pegboard task was manipulated by placing and removing the pegs and manipulation of handedness was made via right and left hand execution. Two mental workload metrics were obtained by electroencephalographic analysis: EEG-cognitive index, and EEG-workload index.

RESULTS: The index of difficulty analyses indicated lower movement time when removing the pegs (low index of difficulty) compared to placing the pegs (high index of difficulty). EEG-workload index was higher when placing the pegs than removing. The handedness analyses indicated lower movement time with the right hand compared to the left hand. However, similar levels of mental workload were found. CONCLUSION: Results suggest higher mental effort when index of difficulty is increased, but not when the left non-dominant hand is performing the task.
\end{abstract} KEYWORDS: motor control| difficulty of the task | Fitts' law| laterality| Grooved Pegboard test| manual task

\section{INTRODUCTION}

Two fundamental factors involved in the performance of manual movements are the index of the difficulty of the task and the handedness. Fitts' law predicts linear increases in movement time with increases in the index of difficulty (ID) of the task. ${ }^{1}$ The amount of information that humans can process per unit of time is limited, and an increase in the task ID requires more information to be processed. Consequently, the system compensates for the more "difficult" movement by increasing the movement time and enabling the completion of required processing. ${ }^{2}$ Fitts' law has been used as a quantitative definition of difficulty in a variety of research studies in healthy $3,4,5$ and clinical 16,7 populations; imagined movements 8,9 and movements performed in two or three dimensions. $8,10,11$

Differences between hands are observed in several behavioral measures such as movement time and endpoint accuracy. ${ }^{12,13,14}$ As manual movements are primarily controlled by the contralateral cerebral hemisphere, the lateralization of functions in each hemisphere may produce these manual asymmetries. ${ }^{15}$ However, engagement of ipsilateral motor areas is observed mainly in movements performed with the left hand. ${ }^{16}$

\begin{tabular}{l|l|l|l|}
\hline Lelis-Torres, & 2017 & VOL. 11 & N. 1 \\
Ugrinowitsch, \\
$\begin{array}{l}\text { Albuquerque, } \\
\text { Apolinário-Souza, } \\
\text { Lage. }\end{array}$ & & & \\
\end{tabular}


Consequently, access to the resources and capabilities of each cerebral hemisphere seems to differ between the right and left hands. ${ }^{17}$

The decline in performance observed when the task ID is high or when the task is performed with the left hand (by right-handers) could be associated to a higherdegree of mental resources dedicated to the task execution. This process, called mental workload, indicates that we have limited mental resources to perform a task under specific environmental and operational conditions. ${ }^{3}$ Mental workload is induced by the demands of the task, which can be manipulated by perceptual load, cognitive load and motor load. .8,19 $^{2}$ If the access of the hands to the perceptual, cognitive and motor resources of each cerebral hemisphere differs, we can expect different levels of mental workload when the left and the right hands perform the task. Surprisingly, to our knowledge, this topic has not been investigated in the mental workload literature. The impact of ID on mental workload is another important aspect to investigate. More information needs to be processed when task ID is increased; as a consequence, we would expect an increased mental workload. Also surprisingly, Fitts' law has been rarely employed to investigate mental workload. ${ }^{3}$

We hypothesized that a higher level of mental workload would be observed (a) in a higher ID condition of the motor task compared to a lower ID condition, and (b) in left hand execution compared to right hand. The Grooved Pegboard Test was chosen because we could manipulate different IDs (placing and removing the pegs) and handedness in a test that is appropriate for these types of manipulation. ${ }^{20,21}$

\section{METHODS}

\section{Participants}

Twenty-three right-handed (handedness $>.8$ measured by the Edinburgh Handedness Inventory ${ }^{22}$ ) male undergraduate students, all of whom were men with normal or corrected-to-normal visual acuity in both eyes who ranged in age from 18 to 40 years (mean age $=24.1 \pm 4.3$ years), participated in this study. Volunteers had no prior experience with the motor task. This research complied with the tenets of the Declaration of Helsinki and was approved by a local ethics committee. Informed consent was obtained from each participant after receiving a full explanation of the study.

\section{Apparatus and Task}

The B-Alert X10 sensor headset (Advanced Brain Monitoring Inc., Carlsbad, CA, USA) was used to acquire the electroencephalographic measures (EEG). Nine $\mathrm{Ag} / \mathrm{AgCl}$ EEG electrodes were located at F3, Fz, F4 (frontal electrodes), C3, Cz, C4 (central electrodes), P3, POz, P4 (posterior electrodes), according to the international 10-20 system. Bi-polar recordings (F3-F4, C3-C4, Cz-PO, F3-Cz, Fz-C3, Fz-PO) were selected in order to reduce the potential for artifacts generated by movements. Two electrodes on mastoid bones (left and right) were used as reference and ground, two sensors attached to the right clavicle. The sampling rate was 256 samples/s for all channels and transferred in real-time via Bluetooth link to a host computer where the B-Alert software (Advanced Brain Monitoring Inc., Carlsbad, CA) stored and processed the EEG data. B-Alert software classifies the level of task engagement into one of the four levels of alertness (sleep onset, distraction, low engagement and high engagement) and the level of mental workload.

\begin{tabular}{l|l|l|l}
\hline Lelis-Torres, & 2017 & VOL. 11 & N. 1 \\
Ugrinowitsch, \\
Albuquerque, \\
Apolinário-Souza, \\
Lage.
\end{tabular}


The Grooved Pegboard (Lafayette Instruments \# 32035) was used to evaluate the manual motor performance.

The standard procedure for the Grooved Pegboard Test was applied. Participants were instructed to place 25 pegs, one at a time, into the holes as quickly as possible, in a prescribed order. They positioned the pegs from left to right on the board when using their right hand, and placed the pegs in the opposite order when using their left hand. Participants were also timed on their speed for removing the 25 pegs with the right hand, one at time, and placing them back into the receptacle. They were asked to remove the pegs in the reverse order in which they were positioned. ${ }^{23}$ Therefore, high ID condition was defined as placing the pegs and the low ID condition was defined as removing the pegs.

\section{Procedures}

Initially, participants completed the Edinburgh Handedness Inventory.22 Next, the wireless sensor headset (X-10 EEG system) was placed onto the volunteer. Afterwards, the EEG device was connected, the communication port was opened and activated, and the impedance was evaluated via B-Alert software. Technical monitoring was conducted to evaluate the quality of data acquisition. Finally, data acquisition was initialized.

The acquisition of baseline data, called Metric Benchmark, was used to create the individualized EEG profiles required for the Cognitive State and Workload Metrics to be valid and accurate across individuals. Each complete benchmarking session (15 min) included three distinct tasks: 3-choice vigilance task; a Visual Psychomotor Vigilance Task; and an Auditory Psychomotor Vigilance Task. ${ }^{24}$ After the benchmarking session, detailed instructions about the three conditions of execution in the Grooved Pegboard task were provided.

To become acquainted with the task, participants carried out one trial of positioning 10 pegs with the right or left hand (counterbalanced order). This trial was not analyzed and was performed before their respective timed conditions. Afterwards, participants were timed using a stopwatch on their speed for moving the 25 pegs in each condition. The order of conditions was counterbalanced across participants, and EEG acquisition data were recorded separately by trial.

\section{EEG signal processing and data reduction}

All signal processing consisting of (a) filtering and digitization, (b) artifact identification and decontamination, and (c) feature extraction were conducted automatically by the B-Alert software. B-Alert software applies a Notch filter at $60 \mathrm{~Hz}$ to all EEG data to remove environmental artifact. Excursions, spikes and amplifier saturation that related to movement are analyzed in the time domain. Excursions and spikes are automatically identified when the EEG amplitude exceed $40 \mu \mathrm{V}$ over short durations (e.g., between 12$27 \mathrm{~ms}$ ). Amplifier saturation was identified when the amplitude between two data points exceeded predefined thresholds (e.g., $440 \mu \mathrm{V}$ ) or the EEG amplitude approached the maximum or minimum of the amplifier dynamic range. Next, the EEG was deconstructed using a wavelets transformation into the $0-2,2-4,4-8,8-16,16-32,32-64$, and $64-$ $128 \mathrm{~Hz}$ wavelets bands. Excessive muscle activity (EMG) was identified and excluded by wavelets power in the $64-128 \mathrm{~Hz}$ band. ${ }^{25,26}$

A linear discriminant function analysis to detect eye blinks is used. The absolute value of the wavelet coefficients $(0-2,2-4,4-8,8-16$, and $16-32 \mathrm{~Hz})$ from the data points

\begin{tabular}{l|l|l|l}
\hline Lelis-Torres, & 2017 & VOL. 11 & N. 1 \\
$\begin{array}{l}\text { Ugrinowitsch, } \\
\text { Albuquerque, } \\
\begin{array}{l}\text { Apolinário-Souza, } \\
\text { Lage. }\end{array}\end{array}$ & & & \\
\end{tabular}


(50th, 40th 30th, 20th, and 10th) before and after the target data point from FzPOz and $\mathrm{CzPOz}$ were used as variables to classify each data point as an eye blink, theta wave, or non-eye blink. The eye blink region was identified by multiple data points classified as eye blinks. The eye blink region was defined through a fixed distance before the start (e.g., 50 data points) and after the end (e.g., 50 data points) of the eye blink. Decontamination was accomplished by computing mean wavelet coefficients for the $0-2,2-4$, and $4-8 \mathrm{~Hz}$ bins from nearby non-contaminated regions and replacing the contaminated data points. Then, Wavelets bands (except 64-128 Hz) were used to reconstruct the EEG signal. ${ }^{26}$

The data points previously associated with excursions, spikes and saturation were replaced with zero values at zero crossing before and after excursions, spikes and saturations. Lastly, EEG absolute and relative power spectral density (PSD) variables for each 1-s epoch were computed running a Fast-Fourier transform applied using a 50\% overlapping Kaiser window $(\alpha=6.0)$. The PSD values were then scaled to accommodate the insertion of zero values as replacements for the artifact. To obtain the EEG-cognitive metrics a four-class quadratic discriminant function analysis (DFA) was derived for each participant. The model was individualized for each participant using DFA coefficients derived during Metric Benchmark. A linear DFA with two classes was used to obtain the EEG-workload metrics (see detailed explanation in Berka et al. ${ }^{26}$ ).

\section{Measurement and statistical analysis}

To evaluate the degree of mental resources dedicated to the task execution we used two EEG-based measures of cognitive states: (a) task engagement defined as EEGcognitive index and (b) mental workload defined as EEG-workload index. Both measures increase as a function of increasing task demands but the EEG-cognitive index tracks demands for sensory processing and attention resources while the EEG-workload index is a measure of the level of cognitive processes involving working memory load, integration of information and problem-solving. ${ }^{26}$ Therefore, three dependent variables were measured: 1) movement time (MT) based on the Grooved Pegboard performance; 2) EEGcognitive index; 3) EEG-workload index. Movement time was defined as the time required for the participant to move all 25 pegs from the start to the end location. ${ }^{27}$ EEG-cognitive metrics indicated the highest probability of drowsiness using the following classifications: 0.1: Sleep onset, 0.3: Distraction, 0.6: Low Engagement, 0.9: High Engagement. EEGworkload index ranged from 0 to 1 . Both measures increase as a function of increasing task demands, but the engagement measure tracks demands for sensory processing and attention resources, while the EEG workload index increases with increasing working memory load and during problem-solving, integration of information, analytical reasoning and may reflect a sub-set of executive functions. ${ }^{26}$

The design of the study with three condition of pegs permitted the following comparisons: right versus left hand in the positioning condition (analysis of handedness) and positioning versus removing with the right hand (analysis of different IDs). The Shapiro-Wilk Test showed normal distribution for the three dependent variables. Thus, Student's $t$ test for dependent samples were conducted. The effect size was calculated using Cohen's formula. ${ }^{28} \mathrm{~A}$ significant difference at the level of 0.05 was adopted for all statistical analyses.

\begin{tabular}{l|l|l|l}
\hline Lelis-Torres, & 2017 & VOL. 11 & N. 1 \\
Ugrinowitsch, \\
Albuquerque, \\
Apolinário-Souza, \\
Lage.
\end{tabular}


Brazilian Journal of Motor Behavior

\section{RESULTS}

\section{Place and remove the pegs with the right hand}

Figure 1 illustrates the means of subjects in terms of: 1) MT to the place task and the removal task with the right hand (Fig.1a), EEG-workload index (Fig.1b) and EEGcognitive index (Fig.1c). Paired t-tests indicated a significantly faster MT to remove pegs compared to placing pegs [t(22) $=27.03, p<.001]$, and a higher EEG-workload index in the place task compared to the remove task $[\mathrm{t}(22)=3.71, p<.01]$. There was no significant difference between conditions on the EEG-Cognitive index $[\mathrm{t}(22)=.74, p=.46]$.

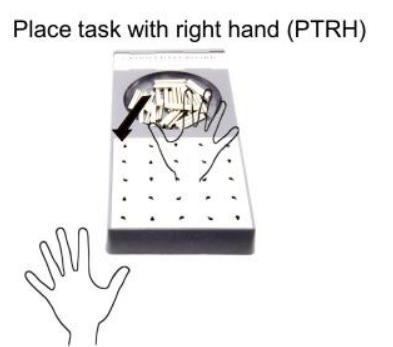

Remove task with right hand (RTRH)

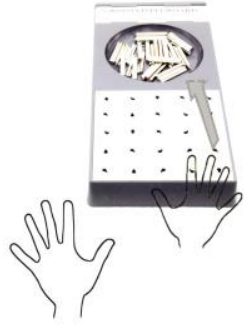

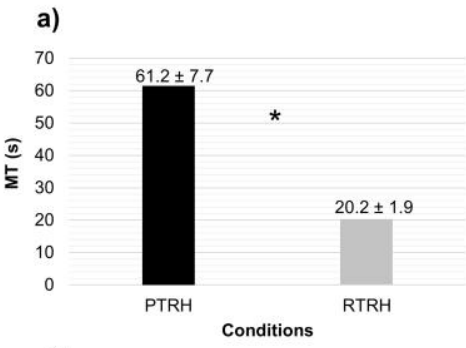

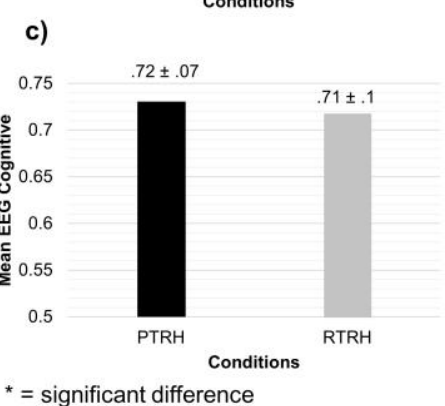

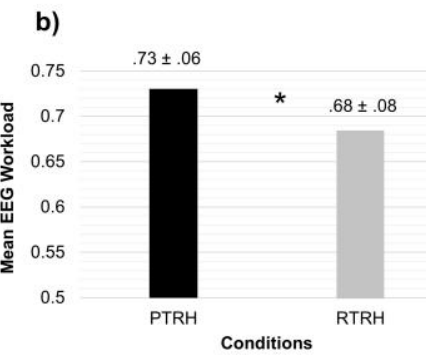

\footnotetext{
Remove task performed faster than the place task.

Place task produced higher workload than the remove task.

a Same engagement level to the place and remove conditions.
}

Figure 1. Means and standard deviations of (a) movement time, (b) EEG-workload index and (c) EEGcognitive index in the place and remove tasks.

\section{Placing of the pegs with the right and left hand}

Figure 2 illustrates the mean of subject in terms of: 1) MT for the place task with the right and the left hand (Fig.2a), EEG-workload index (Fig.2b) and EEG-cognitive index (Fig.2c). Paired t-test indicated a significantly faster MT for the right hand compared to the left hand $[\mathrm{t}(22)=-4.75, \mathrm{p}<.001]$. There was no significant difference between conditions in the EEG-workload index [t(22) $=1.38 . p=.18]$, and EEG-Cognitive index $[\mathrm{t}(22)=.02$, $p=.97]$. 

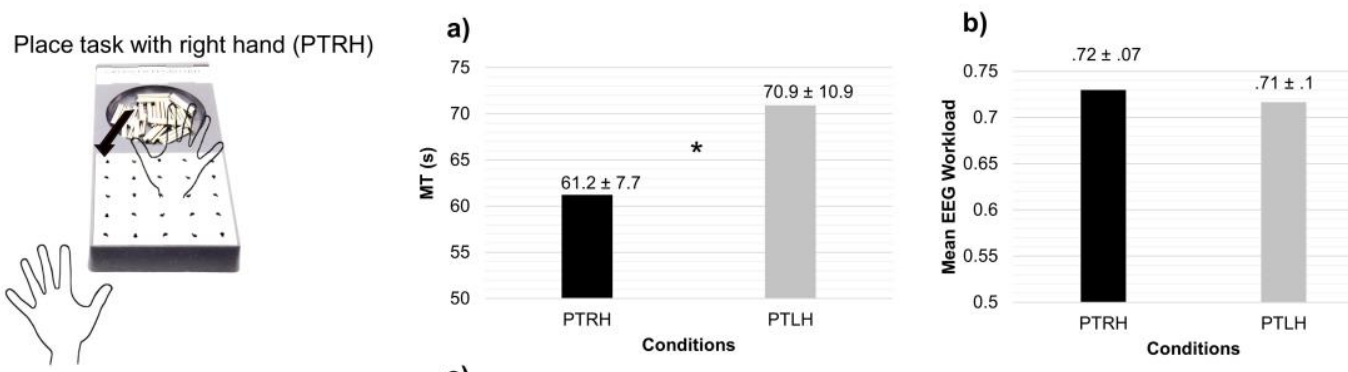

Place task with left hand (PTLH)
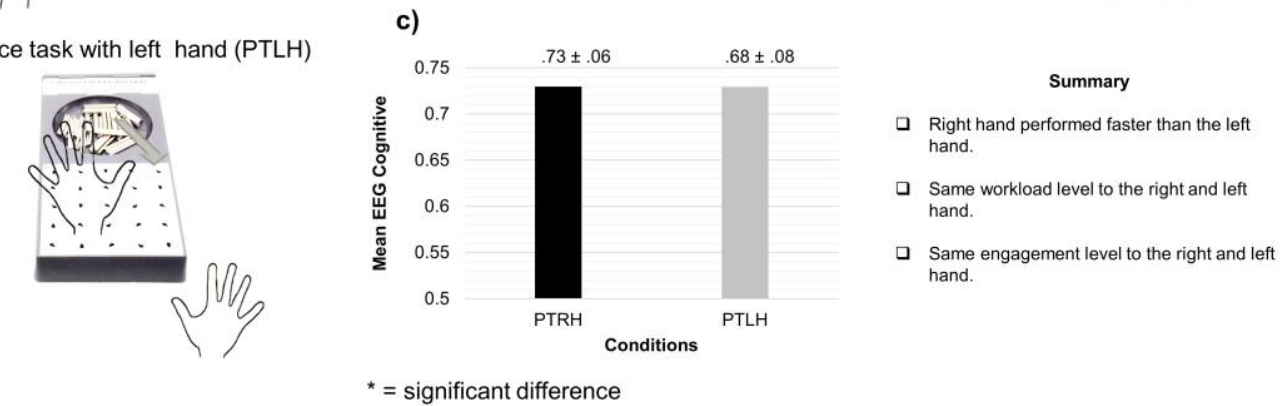

= significant difference

Figure 2. Means and standard deviations of (a) movement time, (b) EEG-workload index and (c) EEGcognitive index in the place task with the right and the left hand.

\section{DISCUSSION}

We investigated the relation between mental workload and (a) ID of the motor task, and (b) handedness. We hypothesized that a higher level of mental workload would be observed to the higher ID condition compared to the lower ID condition, as well as a higher level of mental workload to the left hand execution compared to the right hand. Our hypotheses were partially confirmed. Only the ID factor markedly influenced the mental workload.

Mental workload is the amount of mental resources which is dedicated to a particular cognitive activity. Higher levels of mental workload in the task indicate higher difficulty on the performance of the task. ${ }^{29}$ Previous works comparing placing and removing pegs in the Grooved Pegboard have shown that the task demands affect the manual performance. ${ }^{20,23}$ One fundamental aspect involved in these two conditions is the extreme difference in the ID involved in placingvs. removing the pegs. Corroborating the results of Bryden and Roy ${ }^{20}$ and Bryden and Roy, ${ }^{23}$ we also observed that participants were faster at removing (low ID condition) vs. placing (high ID condition) the pegs.

We took one step further by observing that the difference in the IDs of the task was associated with different levels of mental workload. This type of analysis has been rarely employed in the study of mental workload ${ }^{3}$ mainly using electroencephalographic analysis. The amount of information that human can process per unit of time is limited and an increased ID requires more information to be processed. ${ }^{1}$ The attempt to cope with the higher demand of placing the pegs increased the mental effort involved in the task. The efficient allocation of neural resources is crucial to meet the demands of planning and monitoring the sequential movements of the place task. As task difficulty increases, regional cerebral blood flow increases in areas associated with planning, requiring greater visuomotor processing..$^{30}$ Movement planning and movement control involve two stages of

\begin{tabular}{l|l|l|l}
\hline Lelis-Torres, & 2017 & VOL. 11 & N. 1 \\
Ugrinowitsch, & & & \\
Albuquerque, \\
$\begin{array}{l}\text { Apolinário-Souza, } \\
\text { Lage. }\end{array}$ & & & \\
\end{tabular}


a problem-solving process: the first requires the predetermination of a plan of action aimed at achieving a goal, and the second involves monitoring and guiding the execution of a plan to a useful conclusion. ${ }^{31,32}$ Mental workload reflects a sub-set of executive functions involved in planning and monitoring that possibly are more required in placing the pegs due to the greater visuomotor demand. As an example, an increase in working memory load is associated with a concomitant increase in mental workload. ${ }^{26}$

Interestingly, there was no difference between conditions in the EEG-cognitive index. The level of engagement in both conditions was classified as low engagement (index values between .6 and 8.9). This result assured that in both conditions the level of attentional resources was identical, and the main difference was in the specific allocation of other neural resources. The same result was found when comparing the level of engagement of the place task executed with the right and the left hand. We can conclude that despite the asymmetry observed in the motor behavior there was no attentional asymmetry when comparing the execution by hands. More importantly, we did not find differences in the level of mental workload induced by the hands.

The engagement of ipsilateral motor areas is observed mainly in movements performed with the left hand. ${ }^{16}$ Therefore, we assumed that higher mental workload should be observed because the left hand execution requires more resources and capabilities than the right hemisphere. However, the results observed in our study permitted us to infer that higher engagement of ipsilateral hemisphere expected in movements performed with the left hand does not increase the mental workload measured by EEG. This assumption needs to be investigated in further studies. It is very plausible to expect the same executive demands of planning and monitoring for both hands, as consequence, the same level of mental workload. Therefore, the difference observed in hands performance seems to be specific to the specialization of motor processes in each hemisphere, in which there is a well-known advantage of the left hemisphere with regard to movement time. ${ }^{15}$ Another possible explanation could be related to the level of difficulty of the task performed. The left and the right hands both performed the more difficult variation of the task; it is possible that the high visuomotor demands of the task produced a "ceiling effect" in mental workload. Thus, the difference in the mental effort when controlling the right and left hands is hidden in more demanding tasks.

Altogether, our results indicate that in a manual dexterity task of a sequential nature, only the alteration of the task ID promotes changes in mental workload. Despite the observed performance asymmetry between the right and left hands, the level of mental workload was identical. It is possible that differences in mental workload produced by the left and right handscouldbe observed only in "less difficult" tasks. Further studies are needed to investigate this hypothesis. Few, if any, studies have investigated the mental workload in variations of the same motor task. For the first time, a significant relation between mental workload and ID variation in grooved pegboard task was observed, indicating that it is a promising way to understand the mental effort involved in manual tasks.

\begin{tabular}{l|l|l|l}
\hline Lelis-Torres, & 2017 & VOL. 11 & N. 1 \\
Ugrinowitsch, \\
Albuquerque, \\
Apolinário-Souza, & & & \\
Lage. & & &
\end{tabular}




\section{REFERENCES}

1. Fitts PM. The information capacity of the human motor system in controlling the amplitude of movement. J Exp Psychol Gen 1954; 47(6), 91-381. doi: 10.1037//0096-3445.121.3.262

2. Schmidt RA, Lee TD. Motor control and learning: a behavioral emphasis. 5th ed. Champaign, IL: Human Kinetics; 2011.

3. Jiang $X$, Zheng B, Bednarik R, Atkins MS. Pupil responses to continuous aiming movements. Int J Hum Comput Stud 2015; 83(1): 1-11. doi: 10.1016/j.jihcs.2015.05.006

4. Lage GM, Malloy-Diniz LF, Neves FS, de Moraes PHP, Corrêa H. A kinematic analysis of the association between impulsivity and manual aiming control. Hum Mov Sci 2012; 31(4): 811-823. doi: 10.1016/j.humov.2011.08.008

5. Poletti C, Sleimen-Malkoun R, Temprado JJ, Lemaire P. Older and younger adults' strategies in sensorimotor tasks: Insights from Fitts' pointing task. J Exp Psychol Hum Percept Perform 2015; 41(2): 542-555. doi: 10.1037/xhp0000033

6. Carnahan $\mathrm{H}$, Aguilar $\mathrm{O}$, Malla A, Norman R. An investigation into movement planning and execution deficits in individuals with schizophrenia. Schizophr Res 1997; 23(3): 213-221. doi: 10.1016/s0920-9964(96)00106-5

7. Lage GM, Malloy-Diniz LF, Neves FS., Gallo LG, Valentini AS, Corrêa H. A kinematic analysis of manual aiming control on euthymic bipolar disorder. Psychiatry Res 2013; 208(2): 140-144. doi: 10.1016/j.psychres.2012.09.046

8. Decety J, Michel F. Comparative analysis of actual and mental movement times in two graphic tasks. Brain Cogn 1989; 11(1): 87-97.

9. Personnier P, Kubicki A, Laroche D, Papaxanthis C. Temporal features of imagined locomotion in normal aging. Neurosci Lett 2010; 476(3): 146-149. doi: 10.1016/j.neulet.2010.04.017

10. Jax SA, Rosenbaum DA, Vaughan J. Extending Fitts' Law to manual obstacle avoidance. Exp Brain Res 2007; 180(4): 775-779. doi:10.1007/s00221-007-0996-y

11. Vaughan J, Barany DA, Sali AW, Jax AS, Rosenbaum DA. Extending Fitts' Law to threedimensional obstacle-avoidance movements: Support for the posture-based motion planning model. Exp Brain Res 2010; 207(1-2): 133-138. doi: 10.1007/s00221-010-2431-z

12. Mieschke PE, Elliott D, Helsen WF, Carson RG, Coull JA. Manual asymmetries in the preparation and control of goal-directed movements. Brain Cogn 2001; 45(1): 129-140. doi:10.1006/brcg.2000.1262

13. Serrien DJ, Sovijärvi-Spapé MM. Hemispheric asymmetries and the control of motor sequences. Behav Brain Res 2015; 283(1): 30-6. doi: 10.1016/j.bbr.2015.01.021

14. Woodworth RS. The accuracy of voluntary movement. Psychol Rev 1899; 3(2), 1-106. doi: $10.1037 / \mathrm{h} 0092992$

15. Lavrysen A, Heremans E, Peeters R, Wenderoth N, Helsen WF, Feys P, Swinnen SP. Hemispheric asymmetries in eye-hand coordination. Neurolmage 2008; 39(4): 1938-1949. doi: 10.1016/j.neuroimage.2007.10.007

16. Verstynen T, Diedrichsen J, Albert N, Aparicio P, Ivry RB. Ipsilateral motor cortex activity during unimanual hand movements relates to task complexity. J Neurophysiol 2005; 93(3): 1209-1222. doi: 10.1152/jn.00720.2004

17. Lavrysen A, Heremans E, Peeters R, Wenderoth N, Feys P, Swinnen SP, Helsen WF.

\begin{tabular}{l|l|l|l}
\hline Lelis-Torres, & 2017 & VOL. 11 & N. 1 \\
Ugrinowitsch, & & & \\
Albuquerque, \\
$\begin{array}{l}\text { Apolinário-Souza, } \\
\text { Lage. }\end{array}$ & & & \\
\end{tabular}


Hemispheric asymmetries in goal-directed hand movements are independent of hand preference. Neurolmage 2012; 62(3): 1815-1824. doi:10.1016/j.neuroimage.2012.05.033

18. Wickens CD. Multiple resources and performance prediction. Theor Issues Ergon Sci 2002; 3(2): 159-177.

19. Wickens CD. Multiple resources and mental workload. Hum Factors 2008; 50(3), 449-455. doi:10.1080/14639220210123806

20. Bryden PJ, Roy EA. Spatial task demands affect the extent of manual asymmetries. Laterality 1999; 4(1): 27-37. doi: 10.1080/713754327

21. Sivagnanasunderam M, Gonzalez DA, Bryden PJ, Young G, Forsyth A, Roy EA. Handedness throughout the lifespan: cross-sectional view on sex differences as asymmetries change. Front Psychol 2015; 5: 1-9. doi:10.3389/fpsyg.2014.01556

22. Oldfield RC. The assessment and analysis of handedness: The Edinburgh inventory. Neuropsychologia, 1971; 9(1): 97-113. doi: 10.1016/0028-3932(71)90067-4

23. Bryden PJ, Roy EA. A new method of administering the Grooved Pegboard Test: Performance as a function of handedness and sex. Brain Cogn 2005; 58(3): 258-268. doi:10.1016/j.bandc.2004.12.004

24. Stikic M, Johnson RR, Levendowski DJ, Popovic DP, Olmstead RE, Berka C. EEG-derived estimators of present and future cognitive performance. Front in Hum Neurosci 2011; 5: article 70 . doi: $10.3389 /$ fnhum.2011.00070

25. Berka C, Levendowski DJ, Cvetinovic MM, Petrovic MM, Davis G, Lumicao MN, Zivkovic VT, Popovic MV, Olmstead R. Real-EEG analysis of EEG indexes of alertness, cognition, and memory acquired with a wireless EEG headset. Int J Hum Comput Interract 2004; 17(2): 151-170. doi: 10.1207/s15327590ijhc1702_3

26. Berka C, Levendowski DJ, Lumicao MN, Yau A, Davis G, Zivkovic VT, Olmstead RE, Tremoulet PD, Craven PL. EEG correlates of task engagement and wental workload in vigilance, learning, and memory tasks. Aviat Space Environ Med 2007; 78(5): B231-B244.

27. Bryden PJ, Roy EA, Rohr LE, Egilo S. Task demands affect manual asymmetries in pegboard performance. Laterality 2007; 12(4): 364-377. doi: 10.1080/13576500701356244

28. Cohen J. Statistical power analysis for the behavioral sciences. Mahwah, NJ: Lawrence Erlbaum Associates; 1988

29. Cassenti DN, Kelley TD. Towards the Shape of Mental Workload. Proc Hum Fact Ergon Soc Annu Meet 2006; 50(11): 1147-1151.

30. Winstein CJ, Grafton ST, Pohl PS. Motor task difficulty and brain activity: Investigation of goal- directed reciprocal aiming using positron emission tomography. J Neurophysiol 1997; 77(3): 1581-1594.

31. Glover S, Wall MB, Smith AT. Distinct cortical networks support the planning and online control of reaching-to-grasp in humans. Eur J Neurosci 2012; 35(6): 909-915. doi:10.1111/j.1460-9568.2012.08018.x

32. Spiegel MA, Koester D, Schack T. The functional role of working memory in the (re-) planning and execution of grasping movements. J Exp Psychol Hum Percept Perform 2013; 39(5):1326-1339. doi:10.1037/a0031398

Citation: Lelis-Torres N, Ugrinowitsch H, Albuquerque MR, Apolinário-Souza T, Lage GM. The level of mental workload related to the index of difficulty of motor task and handedness. BJMB 2017: 11(1): 1-10.

\begin{tabular}{|c|c|c|c|}
\hline $\begin{array}{l}\text { Lelis-Torres, } \\
\text { Ugrinowitsch, } \\
\text { Albuquerque, } \\
\text { Apolinário-Souza, } \\
\text { Lage. }\end{array}$ & 2017 & VOL. 11 & N. 1 \\
\hline
\end{tabular}


Brazilian Journal of Motor Behavior

\section{Research Article}

Editor: Joao A. C. Barros, California State University Fullerton, Fullerton, CA, USA.

Copyright: @ 2017 Lelis-Torres, Ugrinowitsch, Albuquerque, Apolinário-Souza, Lage and BJMB. This is an openaccess article distributed under the terms of the Creative Commons Attribution-NonCommercial-NoDerivatives 4.0 International License which permits unrestricted use, distribution, and reproduction in any medium, provided the original author and source are credited.

Funding: This study was funded by Fundação de Amparo à Pesquisa do Estado de Minas Gerais (FAPEMIG) (Edital Universal 2013: Processo No: APQ-02134-13) and Pró-Reitoria de Pesquisa (PRPq) - UFMG (incentive program for publication in indexed journals).

Competing interests: The authors have declared that no competing interests exist.

Download: http://socibracom.com/bjmb/index.php/bjmb/issue/view/38

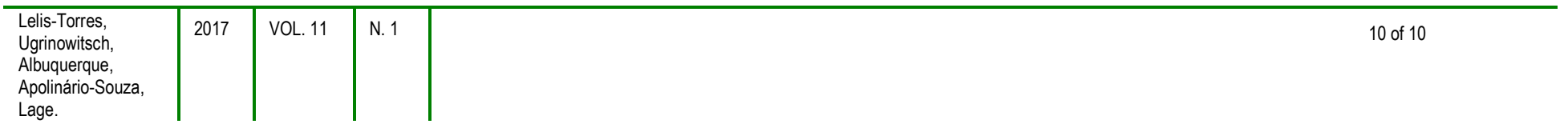

